\title{
BILINGÜISMO PARAGUAYO: ASPECTOS HISTÓRICOS, CULTURALES Y LINGÜÍSTICOS
}

\author{
ÍGOR PROTSENKO
}

Universidad del Norte, Paraguay

\begin{abstract}
Resumen. En el presente artículo se analizan las peculiaridades de la situación lingüística del Paraguay y los paraguayismos: las unidades lingüísticas del castellano que se contrastan con el español hablado de otros países de América Latina y España y, como resultado, provocan algunas dificultades de comprensión rápida para hispanohablantes, en algunos casos hasta incomprensión. La situación lingüística del Paraguay suele presentarse en términos de un bilingüismo ideal, con ciertos matices del plurilingüismo. Se destaca el desarrollo de jopará o guarañol. Se presta la atención a las peculiaridades semánticas del guaraní y su papel en la formación de la situación lingüística del país. Se analiza el uso de los préstamos de guaraní desde el punto de vista denotativo y connotativo en el habla coloquial y en la literatura paraguaya, y se muestran los cambios semánticos del léxico panhispánico en el Paraguay. Los ejemplos de paraguayismos dados proceden de diferentes obras de la literatura moderna del Paraguay, básicamente de autores como Juan Manuel Marcos y Lita Pérez Cáceres.
\end{abstract}

Palabras claves: bilingüismo, paraguayismos, guaraní, jopará, situación lingüística

\section{INTRODUCCIÓN}

Gaspar N. Cabrera en su artículo Significado de Guairã cita al gran filósofo, teólogo, lógico y politólogo alemán Gottfried Wiilhelm von Leibniz, quien dijo: 'Dadme una lengua bien hecha y os daré una civilización completa' (Cabrera, 1971-72: 2-8).

Según los datos de la Dirección General de Estadística, Encuestas y Censos, la población del Paraguay en el año2019 es de poco más de siete millones de habitantes. La población urbana es mayor que rural (62.1\% - 37.9\%), y casi la mitad de la cual es menor de 26 años. Este dato es relevante y se debe tomar en consideración para el análisis de la situación lingüística del país (En línea 1).

En dicho documento no hay información sobre el porcentaje de la gente que habla en diferentes lenguas. Pero en el año 2002 un famoso antropólogo paraguayo experto en guaraní, Bartomeo Melià, llevó a cabo una investigación 
sobre la situación lingüística del país. Según sus datos, el 27\% de la población habla exclusivamente en guaraní, en español solamente el 7\%, el resto de la gente, más del 60\% es bilingüe. A pesar de que los datos envejecen con el tiempo (en el 2002 Paraguay contaba aproximadamente con unos cinco millones y medio de habitantes, ahora cuenta con poco más de siete millones), sus reajustes no son significativos. De todas formas, hoy en día en el Paraguay la mayoría es bilingüe, la cantidad de monolingües disminuye poco a poco (En línea 2).

La finalidad de este artículo es aproximarse a la situación lingüística del Paraguay desde el punto de vista de la semántica histórica, revelar las raíces de intercambios de diferentes culturas y lenguas que llevaron a la creación de la sociedad multinacional por una parte, pero homogénea por otra.

\section{LAS CARACTERÍSTICAS DEL BILINGÜISMO EN PARAGUAY}

La situación bilingüe estable que se observa en el Paraguay es la única en América Latina. Si en otras regiones del continente, donde la conservación y desarrollo de las lenguas indígenas se basa en la conservación de los grupos étnicos que usan estas lenguas, y la sumisión de esas lenguas al castellano, lo que revela la desigualdad de la población indígena, el Paraguay, al contrario, es un ejemplo de la sociedad que se formó a través de la fusión de los indígenas guaraní con los conquistadores españoles y sus herederos. Actualmente es un ejemplo de sociedad homogénea en todos los aspectos: políticos, económicos, culturales, lingüísticos.

Aunque merece la pena mencionar que últimamente predomina la tendencia a la frecuencia del uso de uno u otro idioma dependiendo del territorio frente a la tendencia no al deslinde.

Así, en Asunción, se oye hablar castellano con mayor frecuencia. La capital obliga usar el castellano como una lengua que se cree posee mayor prestigio en el mundo para poder llevar a cabo debates políticos, negocios con extranjeros, atender a los turistas, etc. En las zonas rurales la gente habla guaraní. Fuera de Asunción lo más importante es cumplir sus deberes laborales, sin prestar la atención a la lengua usada.

Hay varias teorías a la hora de analizar y determinar el fenómeno del bilingüismo. Cada una de ellas propone destacar tanto la lengua dominante como la que no lo es, aseveración esta última que apuntaría a la diglosia.

Refiriéndonos al Paraguay, es difícil hablar de la lengua nativa y no nativa. Ambas, castellano y guaraní, tienen la misma preponderancia, ambas se absorben con la leche de la madre, es decir, ambas son nativas. En este caso es admisible usar el término bilingüismo ideal, equilibrado o ambilingüismo a la situación lingüística del Paraguay. Aunque hay investigadores que afirman que la situación solamente se aproxima al bilingüismo ideal (Beardsmore, 1986: 9). 


\subsection{LA FORTALEZA DEL GUARANÍ EN LA SOCIEDAD PARAGUAYA}

La conservación de la posición tan fuerte y el papel importante de la lengua indígena, guaraní, en Paraguay se explica desde varios puntos de vista. Lo más importante es la historia. Olena Mikina cita la frase famosa 'sin historia no hay futuro' (Mikina, 2012:3).

La importancia de este aspecto es reconocida por Rubín, quien señala que 'el uso lingǘstico en el Paraguay refleja la historia del contacto cultural paraguayo con de la colonización' (Rubín, 1974: 155, citado por Melià, 2012: 74). Además, hay que contar con los factores socio-psicológicos (Melià, 2013: 59), con la mestización, adaptación recíproca social y psicológica de los aborígenes y conquistadores en el proceso de la creación de la sociedad socio-cultural monolítica. Bartomeo Melià, analizando la situación lingüística del Paraguay desde este punto de vista, determina el bilingüismo en el país como bilingüismo folklórico (ibid.: 59). Según la afirmación de Antonio Guasch:

Psicológicamente, español y guaraní se constituyen, cada uno por su parte, en la lengua de razón y la lengua del corazón, lo culto y lo íntimo: el guaraní es 'el habla del compromiso de y de la intimidad, del amor y del dolor, de una raza legendaria sacrificada hasta el heroísmo [...]. (Guash, 1956: 11, citado en Melià, 2013: 59)

[...] El pueblo estudia y piensa en castellano, pero ama, odia y pelea en guaraní. (Benítez, 1955: 171, citado en Melià, 2013: 60)

En el arraigue de las lenguas europeas jugó un papel importante la religión. Los misioneros difundían el cristianismo y paralelamente enseñaban su idioma para que los aborígenes entendieran las oraciones, las prédicas y los sermones.

No debemos olvidar que los europeos llevaron su cultura, su propia percepción del mundo, que exigía el uso de su lengua, y esto llevaría a que una de las culturas se convirtiera en la dominante. Tal como la lengua es una parte de la cultura, instrumento para el conocimiento del Universo y de todo lo nuevo, al no comprender esto, los aborígenes no tuvieron otro remedio que asimilar la cultura y la lengua de los conquistadores. Esto provocó la desaparición o la perdida de las funciones principales de las lenguas indígenas en todo el continente americano, con la excepción del Paraguay.

¿Por qué? Nuestra hipótesis se basa en la historia del desarrollo del país y en la situación geográfica que ocupa Paraguay, su alejamiento de los territorios costeros.

Las relaciones comerciales, políticas y culturales no eran fáciles, al revés, complicadas. Las montañas dificultaban el camino a través del Océano Pacifico, mientras que el Océano Atlántico no presentaba este inconveniente. Pero la distancia a recorrer para llegar al territorio paraguayo es enorme, y a esto se suman otras dificultades: la carencia de caballos, bosques intransitables $y$, por supuesto, el calor espantoso y falta de agua. 
Esos factores influyen en la conservación de la lengua de los indígenas, que se sintieron más libres en la comunicación. Como resultado, el idioma de los conquistadores no pudo lograr su auge, perdió primacía, cediendo a la lengua de los indios guaraní.

Evidentemente, ya desde el siglo XVIII Paraguay se podía considerar un país bilingüe. Fray José Manuel Peramás describe así la situación lingüística del Paraguay en aquel entonces:

Es más, en la misma ciudad de Asunción [...] explicaba en guaraní, desde el púlpito, los misterios de la región y los deberes morales, con gran aplauso y provecho de sus oyentes, los cuales, aunque hablan el español, prefieren se les hable en guaraní, al que conversan entre sí, en campo y en sus casas. (Peramás 1947: 74, original latino de 1793, citado en Melià, 2013: 69)

\subsection{LA COMPRENSIÓN E INTERPRETACIÓN DEL GUARANÍ PARAGUAYO}

Los guaraníes desconocían la escritura. Los primeros conquistadores, al escuchar la lengua de los aborígenes, describían lo que oían e interpretaban los significados de las unidades lingüísticas a su manera. Lo que desde aquel entonces provoca dificultades en la traducción y la comprensión del guaraní.

El problema se agrava ya que en varios periodos de la historia una misma palabra cambiaba su significado. En la Tabla №1 están unos ejemplos (Melià, 2006: 106).

Tabla 1 Cambios semánticos en las palabras del guaraní dependiendo de la época

\begin{tabular}{|l|l|l|l|}
\hline PALABRA & PRE-COLONIAL & $\begin{array}{l}\text { SIGLO XVII } \\
\text { (Montoya) }\end{array}$ & SIGLO XXI \\
\hline Japói & manos abiertas & dar cosas, dar comer & regalo, obsequio \\
\hline Tepy & venganza & venganza, paga & precio de algo \\
\hline Kuatia & marca, dibujo & dibujo, papel & papel, carta \\
\hline Karai & chamán, mago & español, cristiano & señor, bautizado \\
\hline Tupã & $\begin{array}{l}\text { Dios del trueno y de las } \\
\text { lluvias }\end{array}$ & Dios de los cristianos & $\begin{array}{l}\text { Un Dios de los } \\
\text { guaraníes, chaman }\end{array}$ \\
\hline
\end{tabular}

Este fenómeno se debe a

la existencia de las numerosas diferencias dialectales, causadas principalmente por los grandes movimientos migratorios que llevaban hacia horizontes en búsqueda de la Tierra sin Mal "Paraíso terrestre", cada vez más lejanos a los miembros de esa familia lingüística. (Melià, 2001: 102) 
Otra explicación se encuentra en la traducción de los vocablos del guaraní relacionados con el profetismo y catecismo de los indígenas.

Los primeros intérpretes del guaraní fueron a los que llamaron hijos de la tierra, criollos que conocían bien el guaraní. 'Fueron ellos los primeros traductores del catecismo guarani' (Melià, 2003: 117).

La traducción cristiana también les debe a los intérpretes, a veces llamados lenguas (lenguaraces): mitad soldados, mitad aventureros, quienes entraron en contacto con los indios desde el primer momento de la conquista. La función de ellos era buscar palabras amables y buen sentido de conversación, afirmando los lazos de amistad e intercambio entre indios y españoles (ibid.: 118).

En muchos casos los misioneros desconfiaban de esos intérpretes. Ellos traducían palabra por palabra, sin tener en cuenta el sentido general de la frase, ni los nuevos valores semánticos que ciertos vocablos habían adquirido en la lengua de las reducciones jesuíticas.

$\mathrm{Y}$ eso un error enorme porque para entender el guaraní no es suficiente saber de lo que se habla, o sea no solo los tópicos: quién habla, a quién, dónde, cuándo, sino - y sobre todo - de qué se habla, estando en este de qué se habla subsumido el problema del desarrollo histórico de los repertorios lingüísticos y modos de decir actualmente en uso. (Melià, 2013: 74)

A causa de esto surgen varias perspectivas sobre la realidad de la lengua y de la vida del guaraní. "El estudio comparativo de uno de esos textos, del que se tiene juntamente el original guaraní, la traducción hecha por un misionero y por un intérprete, es altamente significativo' (Melià, 2013: 120). Nicolás Ñeengyrú, intérprete, toma por ejemplo palabra tuvicha en su acepción 'superior'; el misionero lo traduce como debe ser 'casique'. Porque la lengua de los guaraníes no tiene término, ni palabra que signifique 'superiores' en común (Melià, 2003: 120).

La frase iñe'ê Tupã reroviahava fue traducida por un intérprete de esta manera: 'pareciéndole bien la palabra de Dios que predicaba', mientras que el misionero la tradujo de esta forma: 'palabras tocantes a la Fe de Dios, las reverenció'. En efecto, el intérprete haciendo la traducción técnica de la expresión Tupã reroviahava redujo el sentido de la 'Fe', no lo captó.

Posibles errores en la interpretación de los vocablos del guaraní están encerrados en la semántica histórica. A veces la etimología es confusa y provoca varias acepciones de una misma palabra. Por ejemplo, Tupã, mencionado más arriba, tiene diferentes significados. En el libro La lengua Guaraní en el Paraguay colonial de Bartomeo Melià, encontramos la siguiente explicación:

Cuando llegaron a aquellas costas de la otra parte del mar, viendo que acá estaban, que llamaban a Dios Pan, que según dicho eran españoles, ellos espantaban diciendo $\mathrm{Tu}$, que es la nota de admiración que esta noción usa cuando se admira; y admirándose de que el 
Creador de todo el Universo le llamasen Pan, ellos decían Tu Pan de donde les quedó llamar a todos Dios Tupa. (ibid.: 236)

El Padre Antonio Ruiz Montoya, en efecto, hace derivar la palabra Tupã de tu y pãa, partículas admirativas de la lengua guaraní (ibid.: 236).

Otro comentario deriva Tupã del verbo typa 'ser' y de sustantivo túva 'padre', que tendría la misma raíz; o bien, tupã estaría compuesto del mismo verbo typa y de ánga 'alma', y significaría 'alma de ser, espíritu de lo que existe', o también 'alma del padre o de los padres' (ibid.: 237). Esta etimología fue elaborada por analogía con la de aña - 'ruido, Diablo, Lucifer' (de ai, la a 'materia, objeto, cuerpo', la $i$ 'úlcera, herida' - figuradamente 'algún problema molesto, malo, malamente y ánga 'alma') (ibid.: 237; Guarania 2010: 59).

Esto concuerda con el pensamiento de los indios, que no adoraban a tupã, porque era bueno, era el dador de los frutos de los bienes, era el padre de la luz y del calor y no necesitaba cultos, mientras que hacían ofendas a aña, para que no les hiciese mal. Los españoles y portugueses, difamando a los moradores y rebajándolo más que a los animales, dijeron que no tenían más religión que la del demonio. (ibid.: 237)

Félix de Guarania ofrece otra explicación. Tupã - 'Dios'. Nombre dado por los españoles a Dios. Para los guaraníes cuya etimología de tũ (pytũ) es 'oscuro, oscuridad', y pã concepto de totalidad. O sea, todo oscuro, incomprensible, por aproximación de significado o ignorancia de la cultura guaraní le aplicaron el concepto cristiano (Guarania, 2010: 473).

Todo lo mencionado más arriba, junto con las peculiaridades del español del Paraguay (Protsenko, 2018: 21-42), provoca unas complicaciones a la hora de entender e interpretar el habla espontanea de los paraguayos.

El proceso histórico del desarrollo del territorio del Paraguay desde primeros pasos de los europeos, dio ciertas ventajas al desarrollo del guaraní, sin someter una cultura a la otra (español-guaraní, guaraní-español), demostrando ambas una buena disposición, lo que llevó a la mezcla de dos culturas y lenguas diferentes, y a la aparición de una tercera lengua en el Paraguay: el jopará, que, de hecho, es la lengua principal del país de hoy. En ocasiones resulta complicado entenderlo, incluso para los hispanohablantes.

Ya en el siglo XVIII el misionero austriaco Martín Dobrizhoffer escribió:

Pues después que los primeros españoles se adoptaron de esta provincia, que antes estaba habitada por los Carios y Guaraníes, tomaron un matrimonio las hijas de los habitantes por falta de niñas españolas y por el trato diario los maridos aprendieron el idioma de las esposas y viceversa, las esposas de los maridos, pero como suele ocurrir generalmente cuando aún en la vejez, se aprende idiomas, los españoles corrompían miserablemente la lengua india y las 
indias la española. Así nació una tercera o sea la que usan hoy en día.

(Dobrizhoffer, 1784: 149-150, cita en Melià, 2013: 69)

\section{LA TERCERA LENGUA DEL PARAGUAY}

Entre el español estándar, con amplia literatura normalizada, y el guaraní vernacular, culturalmente identificado con grupos tribales todavía relativamente autónomos, se establece un continuum lingüístico que se despliega entre el español paraguayo y el guaraní paraguayo que, por analogía con portuñol, spanglish y franglás se califica como guarañol (Melià, 2013: 81), un sistema nuevo en el cual hay función gramatical y estructuración nueva de los repertorios con aportes procedentes tanto de una lengua como de otra (ibid.: 82).

Ese fenómeno obtuvo su propio nombre: jopará 'mezcla, variedad' (Guarania, 2010: 248).

\subsection{EL JOPARÁ Y SUS MANIFESTACIONES}

El fenómeno del jopará se observa en las siguientes áreas:

1) La formación de palabras nuevas, uniendo la raíz de los vocablos de dos lenguas: chamigo - che en guaraní 'mi', amigo del castellano (Marcos, 2013: 76).

2) Guaranismos con morfología y sintaxis del español.

a) a las palabras que están en guaraní se les añaden los marcadores gramaticales del castellano: casa llena de poras - es pluralización hispanizada del guaraní pora 'fantasma' (ibid.: 214). 'Día y noche los presos curuvicaban la piedra' (ibid.: 14). La palabra curuvicaban proviene del guaraní curuví - 'fragmento, trozo', y la terminación $a b a$ es el índice del pretérito imperfecto de indicativo en castellano. La frase puede ser traducida como 'Día y noche los presos estaban triturando las piedras'.

b) el uso de las partículas gramaticales del guaraní junto con unidades lexicales castellanas: '...esta $k o$ es una ciudad enorme... como Buenos Aires, pero sin demasiados curepí... Casi nadie habla inglés, tampoco guaraní, así que manejate en castellano' (ibid.: 275). Partícula ko en guaraní frecuenta en las oraciones declarativas e intensifica la confirmación. La frase dicha se puede entender así 'ésta y no otra ciudad es enorme'. Curepí - es el nombre despectivo para los argentinos y en la lengua de origen, en guaraní, significa 'piel de chancho' (chancho - así se le llama al 'cerdo' en el Paraguay) (ibid.: 280). El verbo manejar en dicha frase se usa en la forma típica paraguaya, mandato de vos en imperativo afirmativo y en este caso tiene sentido ‘Habla!'. Un ejemplo más. 'Vos no vas a poder estudiar luego [...]. Pero usá que algo necesario' (ibid.: 273) - al mandato de vos usá se le añade la partícula guaraní que (ke en la ortografía 
estandarizada de guaraní), pospuesta a los imperativos (ibid.: 280). En ambos casos observamos los paraguayismos gramaticales - el uso de los verbos manejar y usar en imperativo afirmativo con la acentuación a la última sílaba, que es norma para el español del Paraguay y es la consecuencia de influencia del guaraní al castellano (el guaraní normalmente se acentúa la última sílaba).

\subsection{EL JOPARÁ EN LA LITERATURA MODERNA DEL PARAGUAY}

Las manifestaciones del jopará son frecuentes también en la literatura moderna. A continuación se analizan unos ejemplos:

1) '... ningún po guasú del gobierno llegaba hasta allí' (Pérez Cáceres, 2012: 25). Po en el guarani 'mano', guasú 'grande'. En la forma metafórica se entiende 'el que tiene todo el poder en sus manos grandes', es decir, 'gran jefe'.

2) 'Nosotras éramos mitakuñai todavía' (ibid.: 27). Mitakuñai - 'doncella, jovencita'.

3) 'El agua allí es morotí sakã y corre rápido' (ibid.: 29). Morotí 'color blanco, blancura', sakã 'transparente'.

4) Rafael Areco Escobar en su cuento El taxista escribe: 'El taxista se espabiló y, al verme, sonrió y respondió con un claro, chera'a'. Chera'a 'mi amigo"'. Según explica Gaby Rojas Teasdale en un artículo del periódico La Nación, cuando decimos chera'a a una persona le estamos diciendo 'mi espejo, mi imagen', es decir, 'mi amigo íntimo' (En línea 3).

5) En la novela de Juan Manuel Marcos El invierno de Gunter encontramos un dialogo entre la joven protagonista y su tío que es ya un hombre maduro. La chica lee un poema, escrito por ella:

[...] No, solo tenía tres líneas:

A ti te contaron los poetas.

Añado yo este verso:

Ahora eres nosotros [...]

Su tío le contesta: 'Mmm..., no está mal. Si no fuera por el tú, muy español, no estaría nada mal' (Marcos, 2013: 142). Se debe a que en el Paraguay el voseo es más frecuente, el uso del pronombre vos en vez de tú y Usted. El tío de la protagonista, típico paraguayo, diría: 'a vos te contaron'.

Los numerosos monosílabos de carácter constructivo, que tanto al principio como al final de los vocablos se repiten indefinidamente, en la formación de un sinnúmero de dicciones, no se pueden permitir afirmar que el guaraní sea aglutinante en toda la línea, ni mucho menos monosilábico, cuando la inmensa mayoría de las dicciones son bisílabas o parisilábicos con significados variables dependiendo del contexto en el que se usa. Ejemplo: remopotikapámapa. Vocablo está formado por: 
$R e-a)$ sufijo de segunda persona singular de los verbos (remba'apo 'trabajas'); b) sufijo acentuado que indica relaciones de pertenencia en el pasado (Emilianore - lo que fue o perteneció a Emiliano) (Guarania, 2010: 396).

$M o$ - a) nasal de $m b o$, comprende de voz coactiva, que se traduce por hacer (mokambu 'hacer mamar'); b) sufijo átono de modo rogativo (eme'êmo chéve 'dame, te lo ruego') (ibid.: 274). Aceptamos la primera interpretación.

Potī-limpio, estar limpio (ibid.: 386).

$\mathrm{Ka}$ - es abreviatura de kuai 'mandar, mando' (ibid.: 262).

$\mathrm{Pa}$ - sufijo átono de interrogativa simple (ibid.: 368).

$M a$ - sufijo átono de aspecto temporal perfectivo, indica acción culminada, se traduce por 'ya' (ibid.: 268).

$P a ́$ - sufijo acentuado que indica totalidad (ibid.: 368).

Resulta que una sola palabra traduce como '¿Ya has mandado limpiarlo todo?' (Guash, 1956: 22).

Otro ejemplo: el sufijo kue (ibid.: 57):

a) sirve para formar abstractos: Ho'okue ebeja ja'u baguã; ikyrakue toñemée (bepýre) - la carne la dejas para comer; la gordura para vender;

b) indica algo pasado: kokuekue - chacra que fue (chacra abandonada);

c) se usa para formar el plural de adjetivos partitivos y expresar nombres de la clase o grupo determinado: Arasa iporanguénte aipota. Ivaikue topyta ne rymnakuéra paruarã - 'quisiera las guayabas mejores, las peores quédatelas para los cerdos';

d) para indicar la parte del animal o la planta separada de su todo: eru kumanda, jaipe'ata iky'akue chugui - 'trae porotos, vamos a separar los sucios'.

\section{CONCLUSIONES}

Para entender bien el habla de los paraguayos en la vida cotidiana, aunque uno tiene ciertas imágenes del guaraní, hay que tomar en consideración la filosofía del guaraní, la lengua de las imágenes que hasta hoy en día nombran objetos nuevos a su forma. Por ejemplo, la palabra 'avión'. En la novela El invierno de Gunter de Juan Manuel Marcos se puede leer el siguiente fragmento '... ha tenido suerte de conseguir lugar en este avión’ (Marcos, 2013: 47). En la traducción de la misma novela al guaraní encontramos: guyra pepoatãnguéra (Marcos, 2014: 30). Este vocablo se forma de: guyra 'pájaro', pepo 'ala', atã 'duro', nguéra 'todos juntos'. Quiere decir que los guaraníes imaginan el avión como si fuera un pájaro con alas duras. Pero hay otra forma de nombrar avión en guaraní - kurusu veve: kurusu 'cruz', veve 'vuela', es decir el objeto que vuela y tiene forma de cruz. 
Desde fines del siglo XIX en varios países de América Latina, la milanesa se considera una comida típica (la carne pasada por huevo y luego por el pan rallado). Para los europeos se entiende que la palabra proviene de la ciudad italiana Milán y no hace falta explicar qué es eso. Los indígenas no tenían esta comida, pero hoy en día es típica, tradicional y muy popular. Tanto que quieren nombrarla en guaraní. Los paraguayos guaraní hablantes empiezan a llamar esta comida mbujá apyté so'o pe chyryry. Mbujá 'pan', apyté 'dentro', so'o 'carne', pe chyryry 'que se fríe'. Es decir, 'la carne que se fríe dentro del pan'.

Así observamos la tendencia de nombrar los objetos nuevos en la forma descriptiva, usando elementos lingüísticos ya conocidos, evitando préstamos.

Como resultado de la interacción de dos lenguas, el español y el guaraní en el Paraguay de hecho existe y se usa en todos niveles de la vida social la tercera lengua, jopará. Análisis del fenómeno de jopará exige estudios especiales.

Los cambios semánticos de las lenguas, como la reflexión de los cambios de la vida social, llevaron a la aparición de un continuum lingüístico único que caracteriza una sociedad nueva, una mezcla no tanto biológica de las naciones como cultural que permite diferenciar a los paraguayos de sus parientes rioplatenses: los argentinos porteños (de Buenos Aires).

\section{REFERENCIAS BIBLIOGRÁFICAS}

Beardsmore, B. (1986) Bilingualism: Basic principles. Clevedon: Multilingual Matters.

Benítez, J. P. ([1955] 1966) Formación social del pueblo paraguayo. Asunción: América Sapucái. Disponible en http://www.portalguarani.com/340_justo_pastor_benitez/17325 formacion_social_del_pueblo_paraguayo__por_justo_pastor_benitez_html [Consultado el 9 de junio de 2017].

Cabrera, G. N. (1971-1972) Significado de la palabra guairã. Disponible en http://www. portalguarani.com/2731_gaspar_n_cabrera/20543_significado_de_la_palabra guaira_1972_conferencia_de_gaspar_n_cabrera_html [Consultado el $\overline{5}$ de mayo de 2016].

Dobrizhpffer, M. ([1784] 1967-1970) Historia de los Abipones, 3 vol. Resistencia: Universidad Nordeste. Disponible en http://www.portalguarani.com/1673_martin dobrizhoffer/13495_historia_de_los_abipones_volumen_iii_padre_martin_ dobrizhoffer_html [Cōnsultado el 3 de junio de 2018].

Guarania, F. (2010) Enciclopedia. Diccionario etimológico-gramatical. Ñe' ẽ rechauka. Ñe'̃ rekokoatu kuaá. Asunción: Fondex.

Guasch, A. (1956) El idioma guaraní: gramática y antología de prosa y verso. $3^{\mathrm{a}}$ ed. Asunción: Casa América - Moreno Hnos.

Meliá, B. (2003) La lengua guaraní en el Paraguay colonial. Asunción: CEPAG.

Meliá, B. (2006) Mundo Guaraní. Asunción: Arte Nuevo.

Meliá, B. (2013) La tercera lengua del Paraguay. Asunción: Servilibro.

Míkina, O. (2012) Historical-semantic research of Latin and Romance verbs in the Indo-European background. Donetsk: Yugo-Vostok.

Protsenko, I. (2018) Situación lingüística del Paraguay. Paraguayismos en la novela "El invierno de Gunter" de Juan Manuel Marcos. Asunción-Kyiv: BVL Publishing. 


\title{
RECURSOS DIGITALES
}

[En línea 1] Disponible en http://www.dgeec.gov.py/ [Consultado el 3 de junio de 2019].

[En línea 2] Disponible en http://ea.com.py/v2/el-87-de-la-poblacion-paraguaya-hablaguarani/ [Consultado el 20 de mayo de 2019].

[En línea 3] Disponible en http://www.tubabel.com/definicion/42656-chera-a [Consultado el 3 de abril de 2019].

\section{RECURSOS DE ANÁLISIS EMPÍRICO}

Marcos, J. M. (2013) El invierno de Gunter. Asunción: Servilibro.

Marcos, J. M. (2014) Gunter araro'y. Asunción: Editorial de la Universidad del Norte.

Pérez Cáceres, L. (2012) Cuentos crueles. Asunción: Editorial de la Universidad del Norte.

\section{PARAGUAYAN BILINGUALISM: HISTORICAL, CULTURAL AND LINGUISTIC ASPECTS}

\begin{abstract}
In the current article we analyze the special features of the current linguistic situation of Paraguay and its paraguayisms: the linguistic units of Spanish which are contrasted with the Spanish spoken in other countries of Latin America and Spain and, as a result, cause some difficulties of quick understanding for speakers of Spanish, in some cases, some misunderstanding. The linguistic situation of Paraguay is commonly described as that of an ideal bilingualism with certain nuances of multilingualism. We highlight the development of Jopará or Guarañol (a blend of Spanish and Guarani). We pay attention to the semantic features of Guarani and its role in the development of the linguistic situation of the country. In addition, we analyze the use of loan words of Guarani in the colloquial language and the Paraguayan literature from both the denotative and connotative viewpoint, and we show the semantic changes of the Pan-Hispanic vocabulary in Paraguay. The instances of paraguayisms provided in this study come from different works of the modern literature of Paraguay written by such authors as Juan Manuel Marcos and Lita Pérez Cáceres.
\end{abstract}

Key words: bilingualism, paraguayisms, Guaraní, Jopará, linguistic situation

Ígor Protsenko (Dr. en Filología Románica, Coordinador Académico de la Facultad de Estudios de Postgrado) trabaja en la Universidad del Norte (UniNorte) de Asunción. Sus intereses académicos incluyen la semántica histórica, lingüística comparativa y tipológica, sociolingüística, lenguas de los aborígenes de América Latina. Correo electrónico: protsent2002@mail.ru 